\title{
Effect of single post-ovulatory administration of levonorgestrel on gene expression profile during the receptive period of the human endometrium
}

\author{
M F Vargas ${ }^{1}$, A A Tapia-Pizarro',4, S P Henríquez'1, M Quezada1', A M Salvatierra², G Noe ${ }^{2}$, \\ D J Munroe ${ }^{3}$, L A Velasquez ${ }^{1,4}$ and H B Croxatto ${ }^{1,4}$ \\ ${ }^{1}$ Universidad Santiago de Chile, Santiago, Chile \\ ${ }^{2}$ Instituto Chileno de Medicina Reproductiva (ICMER), Santiago, Chile \\ ${ }^{3}$ Advanced Technology Program, SAIC-Fredrick Inc, NCl-Frederick, Frederick, Maryland 21702, USA \\ ${ }^{4}$ Centro para el Desarrollo de la Nanociencia y la Nanotechnologia (CEDENNA), Santiago, Chile
}

(Correspondence should be addressed to H B Croxatto at Universidad Santiago de Chile; Email: horacio.croxatto@usach.cl)

\begin{abstract}
The hypothesis that levonorgestrel (LNG) used as an emergency contraceptive interferes with endometrial receptivity remains unproven. We compared the endometrial gene expression profile during the receptive period after administering a single dose of $L N G 1.5 \mathrm{mg}$ or placebo on day 1 of the luteal phase. An endometrial biopsy was done on day $\mathrm{LH}+7 \mathrm{or} \mathrm{LH}+8$ and samples were taken from seven volunteers, each one contributing with one cycle treated with placebo and another with LNG. The expression of 20383 genes was determined using cDNA microarrays. Real-time RT-PCR was used 1) to confirm the differences found in DNA microarray analysis and 2) to determine the effect of LNG on transcript levels of $C 3, C 4 B P \alpha$, COX2, MAOA, S100A4, and SERPINB9, known to be upregulated during receptivity, and on cPLA2 $\alpha, J A K 1, J N K 1, C T S L 1$, and GSTP1, known to respond to mifepristone. Additional endometrial biopsies were done during the pre-receptive $(\mathrm{LH}+3)$ and receptive $(\mathrm{LH}+7)$ period and samples were taken from eight untreated volunteers in order to determine the changes associated with acquisition of receptivity of 14 genes. Mean levels of PAEP, TGM2, CLU, IGF2, and IL6ST mRNAs increased after administering LNG while those of HGD, SAT1, EVA1, LOC90133, ANXA1, SLC25A29, CYB5A, CRIP1, and $S L C 39 A 14$ decreased. Except for the level of $A N X A 1$ transcript, all changes remained within the range observed in untreated controls, and none of the transcripts responding to mifepristone changed in response to LNG. Post-ovulatory administration of LNG caused minimal changes in gene expression profiling during the receptive period. Neither the magnitude nor the nature or direction of the changes endorses the hypothesis that LNG interferes with endometrial receptivity.
\end{abstract}

Journal of Molecular Endocrinology (2012) 48, 25-36

\section{Introduction}

Implantation requires the development of a receptive endometrium able to respond to signals from the blastocyst (Pope 1988). The action of progesterone on an estrogen-primed endometrium results in a particular gene expression profile that renders the endometrium receptive to embryo implantation (Martin et al. 2002).

Levonorgestrel (LNG) is a progestin widely used for regular hormonal contraception, and more recently for emergency contraception. Scientific evidence on the mode of action of LNG as an emergency contraception began to unfold after the method had been introduced in many countries. This situation fostered much debate when this method was introduced in more conservative societies due to the belief that LNG can alter endometrial receptivity and prevent implantation. Administration of LNG during the follicular phase interferes with ovulation in $93 \%$ of cycles treated before the onset of the LH surge (Croxatto et al. 2004), implying that most of the contraceptive efficacy of LNG may be accounted by its interference with ovulation. This is supported by a recent study reporting that none of the 34 women at risk who took LNG before ovulation became pregnant while three pregnancies were recorded among 17 women who took LNG after ovulation (Novikova et al. 2007).

Experiments in monkeys, Cebus apella, and rats have shown that LNG interferes with ovulation but not with implantation (Müller et al. 2003, Ortiz et al. 2004). Although extrapolation of these results to humans has limitations, they give no support to the notion that LNG interferes with endometrial receptivity. Ethical considerations prevent from reproducing those experiments in humans, so alternative approaches need to be used to tackle with this issue. An indirect approach to assess the possible interference of LNG with endometrial receptivity in humans is to determine its 
effects on endometrial morphological or molecular parameters during the period of receptivity. Treatment on day $\mathrm{LH}-2$ had no effect on endometrial morphology assessed at the expected time of endometrial receptivity (Marions et al. 2002) and post-ovulatory treatment administered on day $\mathrm{LH}+2$ had no consistent effect on endometrial morphology or markers of receptivity (Durand et al. 2001, 2005, Marions et al. 2002).

The gene expression profile temporally associated with the acquisition of endometrial receptivity has been established in untreated normal women utilizing microarrays (Carson et al. 2002, Kao et al. 2002, Borthwick et al. 2003, Riesewijk et al. 2003, Mirkin et al. 2005, Haouzi et al. 2009, Talbi et al. 2006), but the effect of LNG on global gene expression profile in the human endometrium has not been reported.

Here, we report the effect of post-ovulatory administration of LNG on endometrial gene expression profile during the period of receptivity in normal healthy women unexposed to the risk of pregnancy.

\section{Materials and methods}

\section{Participants}

The study protocols were approved by the ethics and scientific review committee that serves Instituto Chileno de Medicina Reproductiva (ICMER) in accordance with the Declaration of Helsinki. Two groups of eight women were recruited for the study. Each volunteer signed an informed consent form before participating. All were in good health as determined by medical history, physical and gynecological examination. The mean body mass index was $26 \cdot 8 \mathrm{~kg} / \mathrm{m}^{2}$ (range 23.4-30), mean hemoglobin $14.3 \mathrm{~g} / \mathrm{dl}$ (range 12.7-15.6), and mean age 36 years (range 32-39). A Papanicolaou smear was done as required. All volunteers had been surgically sterilized at least 1 year before, for reasons unrelated to this study, and had regular menstrual cycles within the range 24-35 days. None was under a chronic treatment or had used hormones or drugs able to modify the metabolism of steroid hormones in the preceding months.

\section{Study design}

The first part of the study was a placebo-controlled, crossover, double-blind, randomized trial done with the participation of eight volunteers. Each subject contributed with one placebo-treated cycle (control) and one LNG-treated cycle (experimental) in a randomized order with two resting cycles between them. Four started their participation with the control cycle and the other four with the experimental cycle. They received two placebo pills in the control cycle and two LNG pills of $0.75 \mathrm{mg}$ in the experimental cycle. Placebo pills identical in appearance to LNG pills were provided by Laboratorios Silesia S.A., Santiago, Chile. Treatment was given at the clinic under supervision of a nurse in all cases.

When ovulation is suppressed or postponed by LNG, endometrial effects may result from insufficient progesterone secretion rather than from a direct action of the drug. In addition, when LNG interferes with ovulation, its effects on the endometrium are irrelevant for the mechanism of action as there will be no embryo to implant. For these reasons, we choose to administer LNG in the immediate post-ovulatory period, i.e. on the same day the follicular rupture was diagnosed by transvaginal ultrasound (TVU). In order to control the timing of the interventions and insure normality of the cycle under study, beginning in the mid-follicular phase, a venous blood sample for the assay of LH was taken every day and follicular growth was monitored by TVU. Blood sampling and TVU were discontinued once ovulation was detected. Serum LH was measured by enzyme immunometric assays provided by Immunometrics UK (London, UK). When the echo-image of the leading follicle was found to have disappeared, treatments were given immediately. This ensured that LNG was administered within $24 \mathrm{~h}$ of ovulation.

Endometrial samples were collected on $\mathrm{LH}+7$ or $\mathrm{LH}+8$ for convenience to avoid weekends. They were obtained from the uterine fundus, using pipelle catheters (CCD Laboratories, Paris, France). An additional blood sample was taken on that day to determine serum progesterone level. Progesterone was measured by RIA using Coat-ACount Progesterone from Siemens Medical Solutions Diagnostics Products (Los Angeles, CA, USA).

The second part of the study was a straightforward follow-up of the menstrual cycle of another group of eight volunteers selected with the same criteria. Blood samples were drawn daily and TVU was performed as described in each volunteer for a single menstrual cycle in which no treatment was given. Two endometrial biopsies were obtained within that menstrual cycle, one during the pre-receptive $(\mathrm{LH}+3)$ and another in the receptive $(\mathrm{LH}+7)$ phase. For both parts of the study, one piece of biopsy was processed for histological assessment by an independent pathologist, under blind conditions, using the criteria described by Noyes $e t$ al. (1950). The rest was immediately frozen in liquid nitrogen for subsequent RNA isolation for its use in microarray and real-time RT-PCR analysis.

\section{Isolation of RNA}

Total RNA was isolated from tissue samples according to a modification of the method of Chomczynski \& Sacchi (1987), using Trizol reagent (Invitrogen) using the protocol provided by the manufacturer. The quality of RNA was checked using Agilent's Lab-on-a-Chip 
total RNA nano biosizing assay by examining the $18 \mathrm{~s}$ and 28s ribosomal bands. Protein contamination of the isolated RNAs was quantified spectrophotometrically by the $A_{260} / A_{280}$ ratio; this varied between $1 \cdot 8$ and $1 \cdot 9$.

\section{Microarray analysis}

\section{Production of microarray slides}

Oligonucleotide microarrays were produced in the Laboratory of Molecular Technology (Frederick, MD, USA). Oligonucleotides from the Oligator Human RefSet oligos comprising 70mer probes (Operon Biotechnologies, Huntsville, AL, USA) were spotted on polyL-lysine (Sigma) coated glass slides with a MicroGrid II microarrayer (Biorobotics, Cambridgeshire, UK). The oligonucleotide set comprised 20736 genes included in the National Center for Biotechnology Information (NCBI) Human Reference Sequence database. Control staining with SYBR 555 (Paragon, Molecular Probes, Eugene, OR, USA) was performed for quality control.

\section{Synthesis and labeling of cDNA}

Fifteen micrograms of total RNA from each sample obtained from treatment (LNG) and control (placebo) cycles were processed separately as individual samples in order to generate a labeled cDNA. All samples were compared against a Human Universal RNA (Stratagene, La Joya, CA, USA) composed of total RNA from ten human cell lines. Cyanine 3-dUTP or cyanine 5-dUTP (Perkin Elmer, Boston, MA, USA) was enzymatically incorporated into the reverse transcription reaction, using the LabelStar kit according to the recommended procedure of the manufacturers (Qiagen). Five micrograms of cyanine 5-dUTP-labeled cDNA of each endometrial sample were combined with $5 \mu \mathrm{g}$ cyanine 3-dUTP-labeled cDNA from Human Universal RNA. This was done in duplicate and with one dye swap (three mixtures total per sample).

\section{Hybridization of glass oligonucleotide microarrays}

Oligonucleotide microarrays were hybridized as described for cDNA arrays (DeRisi et al. 1997). Each mixture of labeled cDNA (sample and reference) was adjusted to $29 \mu \mathrm{l}$ with elution buffer provided in the LabelStar kit and subsequent addition of $2 \mu$ human COT1 DNA (Invitrogen) and $2 \mu \mathrm{l}$ poly-d(A) ${ }_{40-60}$ DNA (Amersham Biosciences Corp.) (both $10 \mathrm{mg} / \mathrm{ml}$ ), $6 \cdot 3 \mu \mathrm{l}$ of $20 \times \mathrm{SSC}$, and $1.06 \mu \mathrm{l}$ of $10 \%(\mathrm{w} / \mathrm{v})$ SDS. The hybridization solution was heated for $2 \mathrm{~min}$ at $99^{\circ} \mathrm{C}$ and centrifuged for $5 \mathrm{~min}$ at $16000 \mathrm{~g}$. Slides were hybridized in a water bath at $57^{\circ} \mathrm{C}$ for $14-16 \mathrm{~h}$.
After hybridization, slides were washed in $2 \times$ SSC- $0 \cdot 1 \%$ SDS, $1 \times$ SSC, $0.2 \times$ SSC, and $0.05 \times$ SSC for $1 \mathrm{~min}$ each time and finally washed in ultrapure water for $10 \mathrm{~s}$. Before scanning, slides were dried by spinning at $30 \mathrm{~g}$ for $5 \mathrm{~min}$.

\section{Scanning, feature extraction, and analysis}

Fluorescent images from microarray slides were captured using the Genepix 4000 Scanner (Axon Instruments, Inc., Foster City, CA, USA). Feature extraction was done using GenePix Pro 4.0 software (Axon Instruments, Inc.). Spots with high local background or aberrant spot shape were flagged by the software and checked manually. For each slide, the average foreground signal intensity adjusted for local channel-specific background was calculated. Spots with signal intensities in both channels $<100$ were excluded. If at least one channel had intensity above 100 , the intensity under 100 was set at 100 .

\section{Analysis of microarray data}

The images and signal intensity data were stored in the NCI Microarray Data Base supported by the Center for Information Technology of NIH (http://nciarray.nci. nih.gov). All signal intensities from data sets used for the analysis ranged from $0 \cdot 7$ to $1 \cdot 25$. The distribution ratio extracted from microarray images exhibited normal distribution, constant coefficient of variation, and high positive signal. We used twofold above background as the intensity cutoff. Genes selected for further analyses were only those for which data was available in the eight control and eight experimental cycles and showed a statistically significant difference of at least $95 \%$ between the two sets of cycles. Using this analysis, we selected 245 genes, and with this new subset of genes, we performed an unsupervised hierarchical clustering to determine the diversity of the samples and groups according to their gene expression pattern (not shown). From this analysis, we eliminated the data obtained from one volunteer because her profile was the reverse of her assigned group. Hence, we performed a new statistical analysis, excluding the data of the outlier pair of samples, on those genes whose transcript level changed at least twofold in the experimental cycle with respect to the control cycle. Differences between the two sets of cycles were analyzed by paired $t$-test.

\section{Real-time RT-PCR}

One microgram of total RNA from each endometrial sample used for the cDNA microarray analysis and from $\mathrm{LH}+3$ and $\mathrm{LH}+7$ of untreated cycles was treated with DNase I Amplification grade (Invitrogen) and the 
first-strand cDNA was synthesized by reverse transcription using the Superscript III Reverse Transcriptase First-Strand System for RT-PCR (Invitrogen), according to the recommended procedure of the manufacturers. Levels of all genes were measured from each cDNA sample relative to Human Universal RNA reference used for the cDNA microarrays and the expression values were corrected against GAPDH to account for differing amounts of starting material.

Real-time RT-PCR was performed using an ABI PRISM 7900HT sequence detection system (TaqMan) according to the instructions of manufacturers. Prevalidated primers and probes, including glyceraldehyde-3-phosphate dehydrogenase (GAPDH), were designed by Applied Biosystems (Table 1; PE Applied Biosystems, Foster City, CA, USA). Real-time RT-PCR was performed in duplicate using the conditions recommended by the manufacturer. The thermal cycling conditions included an initial activation step at $50{ }^{\circ} \mathrm{C}$ for $2 \mathrm{~min}$ and $95^{\circ} \mathrm{C}$ for $10 \mathrm{~min}$, followed by 40 cycles of denaturing and annealing amplification $\left(95^{\circ} \mathrm{C}\right.$ for $15 \mathrm{~s}, 60{ }^{\circ} \mathrm{C}$ for $\left.1 \mathrm{~min}\right)$.

Quantitative analysis was based on the relative quantification of each gene of interest in the samples of each group using a variation of the 'delta-delta method' $\left(2^{-\Delta \Delta C_{\mathrm{T}}}\right)$ developed by PE Applied Biosystems (Livak \& Schmittgen 2001):

$2^{\left[\mathrm{C}_{\mathrm{T}}(\text { Gene Universal RNA-Gene RNA samples })\right]-\left[\mathrm{C}_{\mathrm{T}} \text { (GAPDH Universal RNA-GAPDH RNA samples)] }\right.}$,

where cycle threshold $\left(C_{\mathrm{T}}\right)$ is the cycle in the amplification reaction in which fluorescence begins to be exponential above the background baseline. The fold change in relative level of each transcript was obtained from the ratio between the median of the control and experimental cycles or between $\mathrm{LH}+7$ and $\mathrm{LH}+3$. A paired $t$-test was done to determine statistically significant differences in fold change between sets of cycles.

Table 1 IDs from Applied Biosystems assay used for gene expression analysis

\begin{tabular}{|c|c|c|c|}
\hline Genes & AB ID & Genes & AB ID \\
\hline$P A E P$ & $\mathrm{Hs} 00171462 \mathrm{~m} 1$ & $C 4 B P_{\alpha}$ & $\mathrm{Hs} 00426339 \mathrm{~m} 1$ \\
\hline TGM2 & Hs00190278_m1 & $M A O A$ & Hs00165140_m1 \\
\hline$C L U$ & $\mathrm{Hs} 00156548 \mathrm{~m} 1$ & C3 & Hs00163811 m1 \\
\hline IGF2 & Hs00171254_m1 & SERPINB9 & Hs00244603_m1 \\
\hline IL6ST & $\mathrm{Hs} 00174360 \mathrm{~m} 1$ & S100A4 & $\mathrm{Hs} 00243201 \mathrm{~m} 1$ \\
\hline$H G D$ & Hs00164847_m1 & $\operatorname{cox} 2$ & Hs00153133_m1 \\
\hline EVA1 & $\mathrm{Hs} 00170684 \mathrm{~m} 1$ & MAPK 8 & $\mathrm{Hs} 00177083 \mathrm{~m} 1$ \\
\hline LOC90133 & $\mathrm{Hs} 00163781 \mathrm{~m} 1$ & JAK1 & $\mathrm{Hs} 01026983 \mathrm{~m} 1$ \\
\hline SAT1 & Hs00161511_m1 & CTSL1 & Hs00377632_m1 \\
\hline$A N X A 1$ & Hs00167549_m1 & PLA2G4A & Hs00996915_m1 \\
\hline SLC25A29 & Hs00402742_m1 & GSTP1 & Hs00168310_m1 \\
\hline CRIP1 & Hs00832816_g1 & & \\
\hline SLC39A14 & Hs00299262_m1 & $G A P D H$ & Hs02758991_g1 \\
\hline
\end{tabular}

\section{Results}

\section{Menstrual cycle features, histological dating, and progesterone levels in placebo- and LNG-treated cycles}

There were no remarkable differences between placebo- and LNG-treated cycles with respect to cycle length and bleeding. Neither histological features of the endometrium nor progesterone levels displayed differences between control and experimental cycles (mean \pm s.D.: control cycle $41 \cdot 8 \pm 14.4 \mathrm{nmol} / \mathrm{l}$; LNG cycle $38 \cdot 6 \pm 14 \cdot 4 \mathrm{nmol} / \mathrm{l}$ ).

\section{cDNA microarray analysis}

Complete data were obtained and analyzed from 20383 out of the 20736 genes spotted in the microarray slides. A total of 15 transcripts $(0.07 \%)$ displayed a statistically significant change $(P<0.05)$ in the expression of at least twofold between LNG and placebo cycles, of which five increased and ten decreased (Table 2). The Multicriteria analysis (MCA) confirmed that there were no remarkable differences between placebo- and LNG-treated cycles with respect to the global gene expression profile (Fig. 1).

\section{Real-time RT-PCR}

\section{Validation of differences in transcript levels found in microarray analysis}

In order to validate the microarray-positive findings, total RNA from each of the 14 samples was subjected to real-time RT-PCR, using the TaqMan system, with appropriate starters for the 15 transcripts shown in Table 3. All values were corrected for differences in loading relative to GADPH.

The transcript levels found in real-time RT-PCR were similar to those found in the microarray analysis, with minor differences that can be attributed to the higher sensitivity of the former technique (Table 3). All differences were statistically significant in the seven LNG-treated samples. The transcript level corresponding to progestagen-associated endometrial protein $(P A E P)$, transglutaminase 2 (TGM2), HGD, spermidine/spermine N-acetyltransferase (SAT1), ANXA1, EVA1, and SLC25A29 genes showed a larger difference between LNG- and placebo-treated cycles with real-time RT-PCR than with microarray analysis, whereas those of clusterin $(C L U)$, insulin-like growth factor 2 (IGF2), cysteine-rich intestinal protein 1 (CRIP1), and SLC39A14 kept the same level of difference and those of CYB5A, LOC90133, and FAU showed a smaller difference than the one found in the microarray 
Table 2 Transcripts showing a mean fold change $\geq 2$ in human endometrium after post-ovulatory administration of LNG, determined by microarrays

\begin{tabular}{|c|c|c|}
\hline \multirow[b]{2}{*}{ UniGene ID } & \multicolumn{2}{|l|}{ Microarrays } \\
\hline & Fold change & $P$ value \\
\hline
\end{tabular}

$\begin{array}{llrr}\text { Genes } & & & \\ \text { PAEP } & \text { Hs.532325 } & 3 \cdot 7 & 0.018 \\ \text { TGM2 } & \text { Hs.517033 } & 2 \cdot 5 & 0.004 \\ \text { CLU } & \text { Hs.436657 } & 2 \cdot 2 & 0.002 \\ \text { IGF2 } & \text { Hs.272259 } & 2 \cdot 0 & 0.008 \\ \text { IL6ST } & \text { Hs.532082 } & 2 \cdot 0 & 0.007 \\ \text { HGD } & \text { Hs.368254 } & -2 \cdot 8 & 0.009 \\ \text { EVA1 } & \text { Hs.116651 } & -2 \cdot 5 & <0.001 \\ \text { LOC90133 } & \text { Hs.101651 } & -2 \cdot 5 & 0.004 \\ \text { SAT1 } & \text { Hs.28491 } & -2 \cdot 3 & 0.005 \\ \text { ANXA1 } & \text { Hs.494173 } & -2 \cdot 2 & <0.001 \\ \text { SLC25A29 } & \text { Hs.578109 } & -2 \cdot 1 & <0.001 \\ \text { CYB5A } & \text { Hs.465413 } & -2 \cdot 1 & <0.001 \\ \text { FAU } & \text { Hs.387208 } & -2 \cdot 1 & 0.017 \\ \text { CRIP1 } & \text { Hs.70327 } & -2 \cdot 0 & 0.002 \\ \text { SLC39A14 } & \text { Hs.491232 } & -2 \cdot 0 & 0.002\end{array}$

analysis. Therefore, differences found by microarray analysis correspond to actual changes caused by treatment with LNG.

\section{Analysis of transcripts responding to $L N G$ in samples taken in the pre-receptive and receptive phase of untreated menstrual cycles}

TaqMan system was used to determine the direction and magnitude of change from the pre-receptive to the receptive phase of untreated menstrual cycles of those transcripts that changed after treatment with LNG. As shown in Table 3, all transcripts whose median level increased after post-ovulatory LNG administration increased significantly from $\mathrm{LH}+3$ to $\mathrm{LH}+7$. On the other hand, all genes that decreased in LNG-treated cycles did not change significantly from pre-receptive to receptive phenotype. ANXA1 was the exception, as its median value increased less during the receptive period after LNG than in untreated cycles.

\section{Effect of $L N G$ on selected transcripts that changes from the pre-receptive to receptive period in untreated men- strual cycles}

Selected transcripts that had previously been found by microarrays to increase during the receptive phase but had not been confirmed by an independent technique were subjected to TaqMan analysis in endometrial biopsies obtained on $\mathrm{LH}+3$ and $\mathrm{LH}+7$ from eight normal fertile women receiving no treatment. We selected these targets from a large set of genes that changed their expression level during the period of endometrial receptivity because we had the primers and probes for analysis. In addition, we studied $M A O A$, SERPINB9, and C4BP $\alpha$ because we previously reported that these genes decrease their expression in infertile women with endometrial origin (Henriquez et al. 2006, Tapia et al. 2008).

All transcripts analyzed increased during the receptive period confirming previous findings with microarrays (Table 4 ). The same transcripts were analyzed by TaqMan in samples taken after LNG or placebo. LNG caused statistically significant changes in four of six transcripts in the range 1.4-1.8 times and no statistically significant changes in the other 2 (Table 4 ).

\section{Effect of $L N G$ on genes that respond to mifepristone}

The effect of LNG on five transcripts that have been reported to respond to mifepristone in endometrial explants was determined. None of these transcripts responded with a statistically significant change to LNG (Table 5).

\section{Discussion}

The current study tested the effect of single postovulatory administration of LNG on the level of thousands of transcripts in order to assess the likelihood it may impair endometrial receptivity.

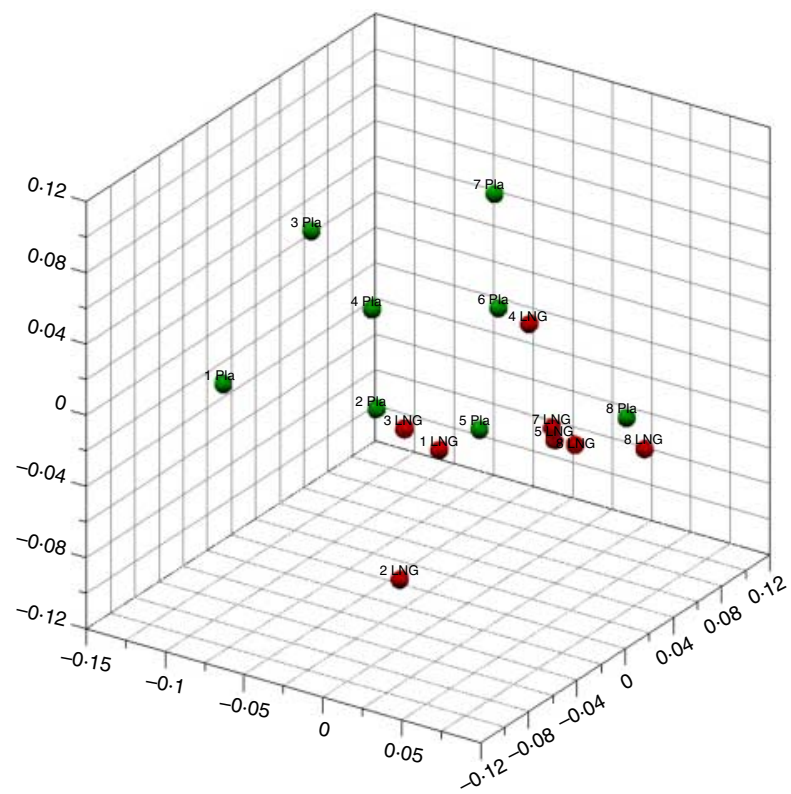

Figure 1 Multicriteria analysis (MCA) of samples obtained during placebo- and LNG-treated cycles showing there were no remarkable differences between placebo- and LNG-treated cycles with respect to the global gene expression profile. Full colour version of this figure available via http://dx.doi.org/10.1530/JME$11-0094$. 
Table 3 Validation by real-time RT-PCR of changes in transcript levels detected by microarrays in human endometrium after post-ovulatory administration of $L N G$ and their level of expression in the pre-receptive $(\mathrm{LH}+3)$ and receptive $(\mathrm{LH}+7)$ phases of the untreated menstrual cycles. The fold change in transcript level determined by real-time RT-PCR derived from the ratio between the median of the placebo- and LNGtreated cycles of all seven volunteers $(A)$ or the ratio between the median of the receptive and pre-receptive phase of eight untreated volunteers (B). The $P$ values are derived from the Wilcoxon matched pairs test. Fold changes marked NS were not calculated because the difference was not significant $(P>0.05)$. Note the wide variations in the range of changes between the samples obtained from different women, especially during the transition from pre-receptive to receptive period where the same gene, in some women increased and in others decreased, indicating that probably the transcript level of these genes is not crucial for the acquisition of receptivity. The genes CYB5 and FAU were not analyzed in control cycles

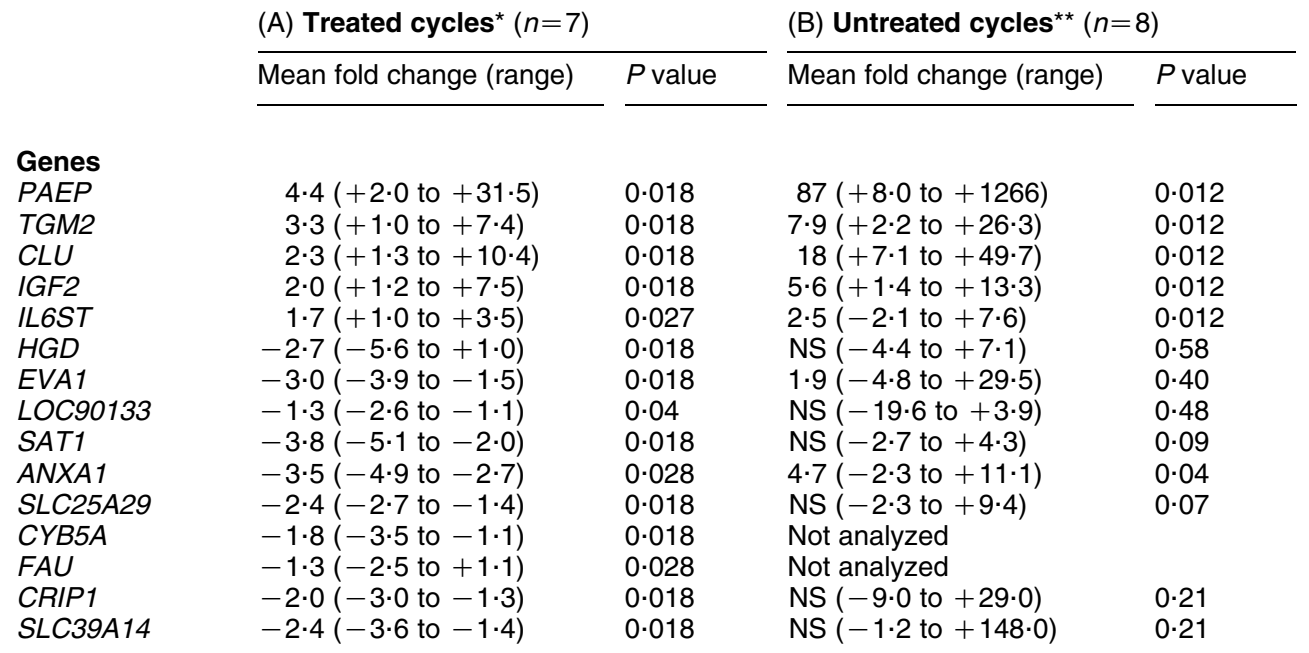

${ }^{*}$ LNG vs placebo; ${ }^{* *}$ receptive vs pre-receptive.

The level of 15 transcripts was found to change in a statistically significant manner after treatment with LNG in the microarray analysis. Those transcripts represent $0.07 \%$ of the genes present in the microarrays.

Previous studies on endometrial gene expression profiling during the window of implantation (Popovici et al. 2000, Carson et al. 2002, Kao et al. 2002, Borthwick et al. 2003, Riesewijk et al. 2003, Mirkin et al. 2005, Talbi et al. 2006, Haouzi et al. 2009) have found a higher number of genes whose expression changed significantly $(1 \cdot 2-9 \cdot 6 \%)$. The lower number of transcripts influenced by LNG may be explained by the concomitant rise in serum progesterone levels and decrease in plasma LNG concentration during the days preceding the biopsy. Presumably, under those

Table 4 Effect in human endometrium of post-ovulatory administration of LNG on the endometrial level of selected transcripts that increase from pre-receptive to receptive phase, determined by real-time RT-PCR. The fold change determined by real-time RT-PCR derived from the ratio between the median of the receptive and pre-receptive phase of eight volunteers $(A)$ or the ratio between the median of the LNG- and placebo-treated cycles of all seven volunteers (B). The $P$ values are derived from the Wilcoxon matched pairs test. Fold changes marked NS were not calculated because the difference was not significant $(P>0.05)$. All transcripts changed significantly by LNG experienced a change smaller than twofold

(A) Untreated cycles* $(n=8)$

UniGene ID
(B) Treated cycles ${ }^{\star \star}(n=7)$

\begin{tabular}{|c|c|}
\hline Mean fold change (range) & $P$ value \\
\hline $1 \cdot 7(+1 \cdot 2$ to $+7 \cdot 0)$ & 0.028 \\
\hline NS $(-1.3$ to $+3 \cdot 6)$ & $0 \cdot 18$ \\
\hline $1.8(-1.3$ to +7.5$)$ & 0.018 \\
\hline $1.7(+1.2$ to $+3 \cdot 8)$ & 0.018 \\
\hline $1.4(+1.3$ to +2.4$)$ & 0.018 \\
\hline$N S(-2.2$ to $+15 \cdot 4)$ & 0.24 \\
\hline
\end{tabular}

Genes
C4BP $\alpha$ or $C 4 B P A$
MAOA
C3
SERPINB9
S100A4
COX2

Hs. 1012

Hs.183109

Hs. 529053

Hs. 104879

Hs.654444

Hs. 196384

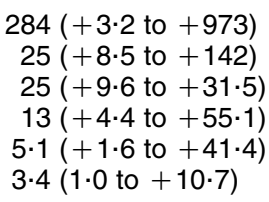

0.012
0.012
0.012
0.012
0.012
0.017

*receptive vs pre-receptive; **LNG vs placebo. 
Table 5 Effect in human endometrium of post-ovulatory LNG administration on transcripts that respond to mifepristone, determined by microarrays or real-time PCR. The fold changes from real-time RT-PCR derived from the ratio between the median of the LNG- and placebo-treated cycles of all seven volunteers. The $P$ values are derived from the Wilcoxon matched pairs test; Fold changes marked NS were not calculated because the difference was not significant $(P>0 \cdot 05)$. None of the genes that responded to mifepristone responded to LNG

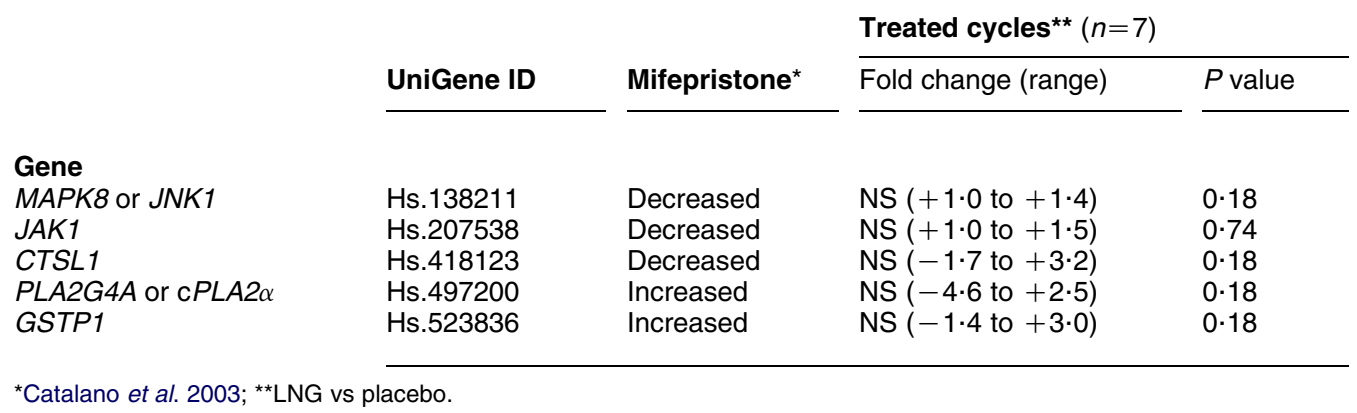

circumstances, both hormones are acting through the same receptor that is likely to be saturated considering it is downregulated in the first half of the luteal phase and the natural ligand concentration is raising. Therefore, it is not surprising that the transcript profile after LNG approximates the one found after placebo. The results of the real-time RT-PCR support our microarray analysis, confirming our findings although false negatives in the microarrays cannot be ruled out, as those were not tested due to practical reasons. Our data showed that all transcripts that increased upon LNG displayed the same regulation in spontaneous cycles in the transition from pre-receptive to receptive state (Table 3). Previous microarray studies have shown that the three transcripts most upregulated in our analysis, $P A E P$, TGM2, and $C L U$, also increased during the window of implantation, supporting our findings. The transcripts of IGF2 and signal transducer of IL6 (IL6ST) displayed smaller changes from pre-receptive to receptive state, where IL6ST has been reported to increase from early to mid-secretory endometrium (Talbi et al. 2006). None of the transcripts downregulated by LNG, except ANXA1, displayed statistically significant changes during the window of implantation. Of these, only CYB5A, SAT1, HGD, and EVA1 have been described previously to change with acquisition of receptivity. However, we found no changes in transcript levels of SAT1 and HGD most likely because they have been described to be regulated from the late proliferative to mid-secretory phase, reflecting changes from an estrogen to a progesterone-dominated endometrium (Kao et al. 2002, Borthwick et al. 2003). EVA1 and CYB5A were reported to decrease from early to mid-secretory phase as in this study (Talbi et al. 2006). EVA1 was also reported to increase during the same period (Carson et al. 2002, Riesewijk et al. 2003). Such discordant results have been described by several endometrial gene expression profile studies that are not readily explained by differences in methodology (Tapia et al. 2011).
Similarly, several transcripts that did not change significantly in our study exhibited high variability between subjects; in some subjects, they appear upregulated while in others they appear downregulated (see range of Table 2). As all women participating in this study were fertile, we speculate that the level of those transcripts is not critical for acquisition of receptivity. The main question remaining is whether or not, at least in theory, the changes found in this study could adversely affect endometrial receptivity. None of the proteins coded by the transcripts affected by LNG have been shown yet to be directly involved in endometrial receptivity; therefore, one can only speculate regarding their potential impact on embryo implantation and clearly functional studies are needed to settle this issue.

Four genes that respond to LNG could be related to the immune response. The first is the gene that codes for PAEP, also known as glycodelin, placental protein 14 , or placental $\alpha 2$-macroglobulin (Seppala et al. 1998, 2002). The direct action of progesterone brings this protein to its highest expression during the human endometrial receptivity period (Taylor et al. 2000). In women who took LNG as an emergency contraceptive 2 days before the LH surge, the concentration of PAEP in uterine flushes measured at $\mathrm{LH}+1$ was significantly elevated when compared with control cycles (Durand et al. 2010). This provides a possible new explanation of the contraceptive effect of LNG around the fertilization window, as it has also been reported that LNG can inhibit sperm-oocyte interaction. PAEP exhibits a potent immunosuppressive activity (Bolton et al. 1987) that has been proposed to help avoid a maternal immune rejection against the embryo at the time of implantation. It is possible that increased endometrial $P A E P$ expression during the receptive period in response to LNG would create a stronger immunosuppressive microenvironment to protect the embryo against immune system response. 
The IL6ST or glycoprotein (gp)-130 (Kamimura et al. 2003) is a molecule that participates in LIF and IL11 signaling. Both bind to their specific receptors IL11R $\alpha$ and LIFR $\beta$, respectively, which heterodimerize with IL6ST for subsequent signaling through the JAK/STAT pathway. Transgenic mice that do not express LIF or IL11 or without the carboxyl-terminal region of gp-130 are infertile due to implantation failure (Ernst et al. 2001, Robb et al. 2002), indicating that the gp-130 signaling cascade is critical to this process. As in this study, IL6ST was reported to increase from early to midsecretory phase (Talbi et al. 2006).

$C L U$ is another gene related to the immune system that displays increased expression in response to LNG. CLU inhibits the final step of the complement cascade, preventing cell lysis by stopping the insertion of the attack complex into cell membranes (Murphy et al. 1998, Jones \& Jomary 2002) and interacts with IgG to increase the rate of formation of insoluble immune complexes (Wilson et al. 1991) implying that CLU could modulate the immune system in the endometrium during the receptive period. In addition, CLU has been reported to be upregulated during the window of implantation (Riesewijk et al. 2003) and downregulated in women with implantation failure (Tapia et al. 2008), suggesting that it is important for the endometrial receptivity acquisition.

Another gene that responds to $\mathrm{LNG}$ and could modulate the immune response is CRIP1. The function of this gene in humans has not been described, but it is known to be preferentially expressed in immune system cells (Khoo et al. 1997). Its expression has been described in human endometrium (Talbi et al. 2006). In transgenic mice, overexpression of CRIP1 alters the cytokine pattern and thus the immune response (Lanningham-Foster et al. 2002). It appears that an overexpression of CRIP1 in this model favors Th2 response over Th1, making it possible to propose a similar role in human endometrium. The expression of this gene decreased twofold in response to LNG and did not change between the pre-receptive and receptive periods, which means it may not have a critical role in the establishment of receptivity.

Another process considered important for endometrial receptivity is the remodeling of the extracellular matrix (ECM) and cell adhesion molecules. One of the molecules we found that had an expression change after post-ovulatory LNG administration that could be related to the remodeling and organization of the ECM in the endometrium is TGM2. This enzyme catalyzes the covalent attachment of proteins and polyamines, both of which contribute to ECM stability in a variety of tissues by interacting with ECM components such as fibronectin and integrins (Fesus \& Piacentini 2002). TGM2 plays an important role in the adhesion and migration of many cell types (Mohan et al. 2003), including the trans-endothelial migration of blood cells, which may mimic the initial step in trophoblast invasion (Fazleabas et al. 2004). While it has been observed that progesterone increases TGM2 transcript expression in Ishikawa endometrial cells (Li et al. 2006), the activity of this enzyme is ten times higher in the secretory endometrium than the proliferative endometrium (Hager et al. 1997). TGM2 mRNA also increases during the period of receptivity (Riesewijk et al. 2003), suggesting that progesterone regulates the expression of TGM2 in vivo. In addition, TGM2 is expressed in pinopodes and co-localizes with the integrin $\alpha v \beta 3$ in the maternal-embryonic interface (Kabir-Salmani et al. 2005). A recent study showed increased protein expression of TGM2 in decidualized vs control endometrial stromal cells (Garrido-Gomez et al. 2011), suggesting a role for TGM2 during implantation. Because the administration of $\mathrm{LNG}$ produced a greater increase than normally occurs during the period of receptivity in a spontaneous cycle, $\mathrm{LNG}$ is not expected to have a deleterious effect on implantation.

The actions of estradiol and progesterone on the endometrium are controlled by paracrine mediators such as the IGF1 and IGF2. The expression of IGF1 and its receptor are stimulated by estrogen, so it is thought that the actions of estrogen-induced cell growth are mediated, at least in part, by IGF1 (Murphy \& Ghahary 1990). Meanwhile, IGF2 has been associated with the characteristic cellular differentiation of the secretory phase (Lopez et al. 1996) with an increase in mRNA levels in the decidualization of ESC (Ganeff et al. 2009). LNG continuously released into the endometrial cavity causes a downregulation of IGF1 mRNA and an increase in IGF2 (Rutanen et al. 1997). This is consistent with the effect of intrauterine LNG release on endometrial morphology, the dominant feature of which is epithelial atrophy and stromal decidualization (Nilsson et al. 1978). Unlike the observation by Rutanen et al. (1997), who reported no difference in IGF2 throughout the menstrual cycle, here we found a $5 \cdot 6$-fold increase in the IGF2 transcript in the receptive period relative to the pre-receptive period. We were probably able to detect this difference because we used real-time RT-PCR, a more sensitive method. We also found that the post-ovulatory administration of LNG causes a twofold increase of this transcript.

Another gene that decreases its expression after LNG administration and could have a role in the endometrium is SAT1. This enzyme limits the bioavailability of the polyamines spermine and spermidine by mediating their mono- or di-acetylation and their subsequent conversion to putrescine. Consequently, the intracellular concentration of polyamines is crucial in cell growth and proliferation, where SAT1 typically functions as a cell growth inhibitor by decreasing the supply of polyamines. Accordingly, transgenic mice 
overexpressing SAT1 have infertility associated with uterine hypoplasia and ovarian hypofunction (Pietila et al. 1997). We found no statistically significant difference in the expression of SAT1 between the prereceptive and receptive state. However, as mentioned above, Borthwick et al. (2003) reported an increased expression of SAT1 during the period of receptivity, though this was not confirmed by real-time RT-PCR. From our results, we speculate that the acquisition of receptivity does not require changes in the expression of SAT1.

ANXA1 was the only transcript presenting a statistically significant decrease in mean level after LNG while it showed a statistically significant increment from prereceptive to receptive state. The mean level of ANXA1 was $3 \cdot 5$-fold lower with LNG (range: $-4 \cdot 9$ to $-2 \cdot 7$, $P=0.028$ ) than in the normal receptive state. Its mean level was $4 \cdot 7$-fold higher in the receptive compared with the pre-receptive state (range: $-2 \cdot 3$ to $+11 \cdot 1, P=0 \cdot 04$ ) (Table 3). Thus, post-ovulatory administration of LNG partially prevented the increase in ANXA1 level that takes place at the onset of receptivity. ANXA1 inhibits phospholipases A2 (cPLA2 $\alpha$ or PLA2G4A; Wallner et al. 1986). It has been described that the inhibition of PLA2 decreases the release of arachidonic acid needed for the synthesis of prostaglandins (PGs) and leukotrienes by cyclooxygenases (COX) 1 and 2. In murine models, PGs are implicated in ovulation and implantation, and mice defective in COX2 show multiple female reproductive failures, such as defective ovulation, fertilization, implantation, and decidualization (Lim et al. 1997). Specific COX2 inhibitors also prevent implantation (Shafiq et al. 2004). In addition, mice defective in cPLA2 $\alpha$ have an abnormal distribution of uterine embryo (Song et al. 2002), suggesting that these enzymes and PG production have a critical role in implantation. High levels of COX2 have been found in human endometrium during the receptive period and decreased expression was reported after post-ovulatory administration of mifepristone (Marions \& Danielsson 1999) but not after the post-ovulatory administration of LNG (Marions et al. 2002). Microarray studies have established that $P L A 2$ increases during the receptive period (Kao et al. 2002, Riesewijk et al. 2003) and also after the administration of mifepristone to explants of endometrium (Catalano et al. 2003). We speculate that following post-ovulatory administration of LNG, the increased level of ANXA1 transcripts that normally occurs in the receptive period was still present, albeit less pronounced, and was associated with a $3 \cdot 4$-fold increase in the transcript level of COX2 (Table 4) with no change in cPLA2 $\alpha$ (Table 5 ).

Additionally, we examined another group of six genes, C4BPQ, MAOA, C3, SERPINB9, S100A4, and $C O X 2$, previously found in microarray analyses mentioned above to be upregulated during the receptive period. To our knowledge, increased expression of C4BPQ, SERPINB9, and S100A4 had not been submitted to confirmation by an independent technique; real-time RT-PCR analysis of biopsies performed in $\mathrm{LH}+3$ and $\mathrm{LH}+7$ confirmed that the level of all these transcripts increase during the transition from non-receptive to receptive state. Our limited resources did not allow us to examine all transcripts that have been reported in previous studies to change at the onset of receptivity. In a separate study, we found that PAEP, CLU, MAOA, C4BPA, and SERPINB9 have markedly decreased expression in women diagnosed with implantation failure of endometrial origin (Henriquez et al. 2006, Tapia et al. 2008, Tapia et al. 2011). PAEP and C4BPA expression is also diminished in women with impaired fertility associated with endometriosis (Kao et al. 2003). In this study, we found only minimal or no differences in the expression of these genes in the endometrium after post-ovulatory administration of LNG.

Finally, we found no change in five genes (Table 5) that previously have been shown to respond to mifepristone in the human endometrium (Catalano et al. 2003) and none of the genes that we found that change with LNG had been reported to change their expression after systemic mifepristone administration in mice (Bagchi et al. 2005). This may seem paradoxical considering that both LNG and mifepristone act through the same receptors, but eliciting opposite effects. Nevertheless, we think that in the experimental settings tested, mifepristone prevents the genomic actions of progesterone through its receptors, while decreasing serum levels of LNG in the early luteal phase, were probably overcome by concomitant increasing levels of endogenous progesterone. It is possible that progesterone receptors whose expression is greatly decreased during the luteal phase are saturated by the high concentration of circulating progesterone causing maximum response, while this situation is ideal to put in evidence the action of an antagonist, it is the least suitable in order to demonstrate agonistic activity. In addition, low doses of mifepristone administered in the luteal phase alter endometrial maturation (Greene et al. 1992, Marions et al. 1999) and other antiprogestins, such as onapristone produce the same pattern of endometrial alterations (Katkam et al. 1995) that will inhibit endometrial receptivity providing a basis of their development for endometrial contraception (Cameron et al. 1997) whereas no effects of post-ovulatory LNG administration on the histological features of the endometrium examined during the receptive phase were found (Durand et al. 2001, 2005, Marions et al. 2002). Furthermore, two independent studies have shown that emergency contraception with LNG given before ovulation prevents pregnancy in all treated 
women and that it fails completely to prevent pregnancy when it is given after ovulation (Novikova et al. 2007, Noe et al. 2010), confirming the use of LNG as an effective contraceptive method only if it is taken before ovulation. Those two studies provide functional evidence that the few changes in gene expression described here are irrelevant for endometrial receptivity.

In summary, under the conditions studied, LNG caused minimal changes in transcripts levels and, considering their nature and magnitude, it is unlikely they would interfere with endometrial receptivity an assumption confirmed by the studies of Novikova et al. (2007) and Noe et al. (2010) cited above.

\section{Declaration of interest}

The authors declare that there is no conflict of interest that could be perceived as prejudicing the impartiality of the research reported.

\section{Funding}

This project was supported by Programa BASAL FB0807 (CEDENNA) of CONICYT and FONDECYT 1090589. This project has been funded in part with federal funds from the National Cancer Institute, National Institutes of Health, under contract HHSN261200800001E. The content of this publication does not necessarily reflect the views or policies of the Department of Health and Human Services, nor does mention of trade names, commercial products, or organizations imply endorsement by the U.S. Government.

\section{Acknowledgements}

We thank all volunteers who participated in this study. We also thank Dr James Cherry for his helpful guidance on real-time RT-PCR.

\section{References}

Bagchi IC, Li Q, Cheon YP, Mantena SR, Kannan A \& Bagchi MK 2005 Use of the progesterone receptor antagonist RU 486 to identify novel progesterone receptor-regulated pathways in implantation. Seminars in Reproductive Medicine 23 38-45. (doi:10.1055/s-2005864032)

Bolton AE, Pockley AG, Clough KJ, Mowles EA, Stoker RJ, Westwood OM \& Chapman MG 1987 Identification of placental protein 14 as an immunosuppressive factor in human reproduction. Lancet 1 593-595. (doi:10.1016/S0140-6736(87)90235-2)

Borthwick JM, Charnock-Jones DS, Tom BD, Hull ML, Teirney R, Phillips SC \& Smith SK 2003 Determination of the transcript profile of human endometrium. Molecular Human Reproduction 9 19-33. (doi:10.1093/molehr/gag004)

Cameron ST, Critchley HO, Buckley CH, Kelly RW \& Baird DT 1997 Effect of two antiprogestins (mifepristone and onapristone) on endometrial factors of potential importance for implantation. Fertility and Sterility 67 1046-1053. (doi:10.1016/S00150282(97)81437-9)

Carson DD, Lagow E, Thathiah A, Al-Shami R, Farach-Carson MC, Vernon M, Yuan L, Fritz MA \& Lessey B 2002 Changes in gene expression during the early to mid-luteal (receptive phase) transition in human endometrium detected by high-density microarray screening. Molecular Human Reproduction 8 871-879. (doi:10.1093/molehr/8.9.871)

Catalano RD, Yanaihara A, Evans AL, Rocha D, Prentice A, Saidi S, Print CG, Charnock-Jones DS, Sharkey AM \& Smith SK 2003 The effect of RU486 on the gene expression profile in an endometrial explant model. Molecular Human Reproduction 9 465-473. (doi:10. 1093/molehr/gag060)

Chomczynski P \& Sacchi N 1987 Single-step method of RNA isolation by acid guanidinium thiocyanate-phenol-chloroform extraction. Analytical Biochemistry 162 156-159. (doi:10.1016/00032697(87)90021-2)

Croxatto HB, Brache V, Pavez M, Cochon L, Forcelledo ML, Alvarez F, Massai R, Faundes A \& Salvatierra AM 2004 Pituitary-ovarian function following the standard levonorgestrel emergency contraceptive dose or a single 0.75 -mg dose given on the days preceding ovulation. Contraception 70 442-450. (doi:10.1016/j.contraception. 2004.05.007)

DeRisi JL, Iyer VR \& Brown PO 1997 Exploring the metabolic and genetic control of gene expression on a genomic scale. Science $\mathbf{2 7 8}$ 680-686. (doi:10.1126/science.278.5338.680)

Durand M, del Carmen Cravioto M, Raymond EG, Duran-Sanchez O, De la Luz Cruz-Hinojosa M, Castell-Rodriguez A, Schiavon R \& Larrea F 2001 On the mechanisms of action of short-term levonorgestrel administration in emergency contraception. Contraception 64 227-234. (doi:10.1016/S0010-7824(01)00250-5)

Durand M, Seppala M, Cravioto Mdel C, Koistinen H, Koistinen R, González-Macedo J \& Larrea F 2005 Late follicular phase administration of levonorgestrel as an emergency contraceptive changes the secretory pattern of glycodelin in serum and endometrium during the luteal phase of the menstrual cycle. Contraception 71 451-457. (doi:10.1016/j.contraception.2005. 01.003)

Durand M, Koistinen R, Chirinos M, Rodríguez JL, Zambrano E, Seppälä M \& Larrea F 2010 Hormonal evaluation and midcycle detection of intrauterine glycodelin in women treated with levonorgestrel as in emergency contraception. Contraception 82 526-533. (doi:10.1016/j.contraception.2010.05.015)

Ernst M, Inglese M, Waring P, Campbell IK, Bao S, Clay FJ, Alexander WS, Wicks IP, Tarlinton DM, Novak U et al. 2001 Defective gp130mediated signal transducer and activator of transcription (STAT) signaling results in degenerative joint disease, gastrointestinal ulceration, and failure of uterine implantation. Journal of Experimental Medicine 194 189-203. (doi:10.1084/jem.194.2.189)

Fazleabas AT, Kim JJ \& Strakova Z 2004 Implantation: embryonic signals and the modulation of the uterine environment - a review. Placenta 25 26-31. (doi:10.1016/j.placenta.2004.01.014)

Fesus L \& Piacentini M 2002 Transglutaminase 2: an enigmatic enzyme with diverse functions. Trends in Biochemical Science 27 534-539. (doi:10.1016/S0968-0004(02)02182-5)

Ganeff C, Chatel G, Munaut C, Frankenne F, Foidart JM \& Winkler R 2009 The IGF system in in vitro human decidualization. Molecular Human Reproduction 15 27-38. (doi:10.1093/molehr/gan073)

Garrido-Gomez T, Dominguez F, Lopez JA, Camafeita E, Quiñonero A, Martinez-Conejero JA, Pellicer A, Conesa A \& Simón C 2011 Modeling human endometrial decidualization from the interaction between proteome and secretome. Journal of Clinical Endocrinology and Metabolism 96 706-716. (doi:10.1210/jc.2010-1825)

Greene KE, Kettel LM \& Yen SS 1992 Interruption of endometrial maturation without hormonal changes by an antiprogesterone during the first half of luteal phase of the menstrual cycle: a contraceptive potential. Fertility and Sterility 58 338-343.

Hager H, Gliemann J, Hamilton-Dutoit S, Ebbesen P, Koppelhus U \& Jensen PH 1997 Developmental regulation of tissue transglutaminase during human placentation and expression in neoplastic trophoblast. Journal of Pathology 181 106-110. (doi:10.1002/ (SICI) 1096-9896(199701) 181:1 < 106::AID-PATH725 > 3.0.CO;2-K) 
Haouzi D, Mahmoud K, Fourar M, Bendhaou K, Dechaud H, De Vos J, Rème T, Dewailly D \& Hamamah S 2009 Identification of new biomarkers of human endometrial receptivity in the natural cycle. Human Reproduction 24 198-205. (doi:10.1093/humrep/ den360)

Henriquez S, Tapia A, Quezada M, Vargas M, Cardenas H, Rios M, Salvatierra AM, Croxatto H, Orihuela P, Zegers-Hochschild F et al. 2006 Deficient expression of monoamine oxidase A in the endometrium is associated with implantation failure in women participating as recipients in oocyte donation. Molecular Human Reproduction 12 749-754. (doi:10.1093/molehr/gal082)

Jones SE \& Jomary C 2002 Clusterin. International Journal of Biochemistry \&o Cell Biology 34 427-431. (doi:10.1016/S1357-2725 (01)00155-8)

Kabir-Salmani M, Shiokawa S, Akimoto Y, Sakai K, Sakai K \& Iwashita M 2005 Tissue transglutaminase at embryo-maternal interface. Journal of Clinical Endocrinology and Metabolism 90 4694-4702. (doi:10.1210/jc.2005-0240)

Kamimura D, Ishihara K \& Hirano T 2003 IL-6 signal transduction and its physiological roles: the signal orchestration model. Reviews of Physiology, Biochemistry and Pharmacology 149 1-38. (doi:10.1007/ s10254-003-0012-2)

Kao LC, Tulac S, Lobo S, Imani B, Yang JP, Germeyer A, Osteen K, Taylor RN, Lessey BA \& Giudice LC 2002 Global gene profiling in human endometrium during the window of implantation. Endocrinology 143 2119-2138. (doi:10.1210/en.143.6.2119)

Kao LC, Germeyer A, Tulac S, Lobo S, Yang JP, Taylor RN, Osteen K, Lessey BA \& Giudice LC 2003 Expression profiling of endometrium from women with endometriosis reveals candidate genes for disease-based implantation failure and infertility. Endocrinology 144 2870-2881. (doi:10.1210/en.2003-0043)

Katkam RR, Gopalkrishnan K, Chwalisz K, Schillinger E \& Puri CP 1995 Onapristone (ZK98, 299): a potential antiprogestin for endometrial contraception. American Journal of Obstetrics and Gynecology 173 779-787. (doi:10.1016/0002-9378(95)90341-0)

Khoo C, Blanchard RK, Sullivan VK \& Cousins RJ 1997 Human cysteine-rich intestinal protein: cDNA cloning and expression of recombinant protein and identification in human peripheral blood mononuclear cells. Protein Expression and Purification 9 379-387. (doi:10.1006/prep.1996.0709)

Lanningham-Foster L, Green CL, Langkamp-Henken B, Davis BA, Nguyen KT, Bender BS \& Cousins RJ 2002 Overexpression of CRIP in transgenic mice alters cytokine patterns and the immune response. American Journal of Physiology. Endocrinology and Metabolism 282 1197-1203. (doi:10.1152/ajpendo.00508.2001)

Li Q, Bagchi MK \& Bagchi IC 2006 Identification of a signaling pathway involving progesterone receptor, calcitonin, and tissue transglutaminase in Ishikawa endometrial cells. Endocrinology 147 2147-2154. (doi:10.1210/en.2005-1116)

Lim H, Paria BC, Das SK, Dinchuk JE, Langenbach R, Trzaskos JM \& Dey SK 1997 Multiple female reproductive failures in cyclooxygenase 2-deficient mice. Cell 91 197-208. (doi:10.1016/S00928674(00) 80402-X)

Livak KJ \& Schmittgen TD 2001 Analysis of relative gene expression data using real-time quantitative PCR and the $2^{-\Delta \Delta C_{\mathrm{T}}}$ method. Methods 25 402-408. (doi:10.1006/meth.2001.1262)

Lopez MF, Dikkes P, Zurakowski D \& Villa-Komaroff L 1996 Insulin-like growth factor II affects the appearance and glycogen content of glycogen cells in the murine placenta. Endocrinology 137 2100-2108. (doi:10.1210/en.137.5.2100)

Marions L \& Danielsson KG 1999 Expression of cyclo-oxygenase in human endometrium during the implantation period. Molecular Human Reproduction 5 961-965. (doi:10.1093/molehr/5.10.961)

Marions L, Viski S, Danielsson KG, Resch BA, Swahn ML, Bygdeman M \& Kovacs L 1999 Contraceptive efficacy of daily administration of $0.5 \mathrm{mg}$ mifepristone. Human Reproduction 14 2788-2790. (doi:10. 1093/humrep/14.11.2788)
Marions L, Hultenby K, Lindell I, Sun X, Stabi B \& Gemzell Danielsson K 2002 Emergency contraception with mifepristone and levonorgestrel: mechanism of action. Obstetrics and Gynecology 100 65-71. (doi:10. 1016/S0029-7844(02) 02006-9)

Martin J, Dominguez F, Avila S, Castrillo JL, Remohi J, Pellicer A \& Simon C 2002 Human endometrial receptivity: gene regulation. Journal of Reproductive Immunology 155 131-139. (doi:10.1016/S01650378(01)00140-1)

Mirkin S, Arslan M, Churikov D, Corica A, Diaz JI, Williams S, Bocca S \& Oehninger S 2005 In search of candidate genes critically expressed in the human endometrium during the window of implantation. Human Reproduction 20 2104-2117. (doi:10.1093/ humrep/dei051)

Mohan K, Pinto D \& Issekutz TB 2003 Identification of tissue transglutaminase as a novel molecule involved in human CD8+ T cell transendothelial migration. Journal of Immunology 171 3179-3186.

Müller AL, Llados CM \& Croxatto HB 2003 Postcoital treatment with levonorgestrel does not disrupt postfertilization events in the rat. Contraception 67 415-419. (doi:10.1016/S0010-7824(03) 00021-0)

Murphy LJ \& Ghahary A 1990 Uterine insulin-like growth factor-1: regulation of expression and its role in estrogen-induced uterine proliferation. Endocrine Reviews 11 443-453. (doi:10.1210/ edrv-11-3-443)

Murphy BF, Kirszbaum L, Walker ID \& d'Apice AJ 1998 SP-40, a newly identified normal human serum protein found in the SC5b-9 complex of complement and in the immune deposits in glomerulonephritis. Journal of Clinical Investigation 81 1858-1864. (doi:10.1172/JCI113531)

Nilsson CG, Luukkainen T \& Arko H 1978 Endometrial morphology of women using a d-norgestrel-releasing intrauterine device. Fertility and Sterility 29 397-401.

Noe G, Croxatto HB, Salvatierra AM, Reyes V, Villaroel C, Muñoz C, Morales G \& Retamales A 2010 Contraceptive efficacy of emergency contraception given before or after ovulation. Contraception $\mathbf{8 1}$ 414-420. (doi:10.1016/j.contraception.2009.12.015)

Novikova N, Weisberg E, Stanczykc FZ, Croxatto HB \& Fraser IS 2007 Effectiveness of levonorgestrel emergency contraception given before or after ovulation - a pilot study. Contraception 75 112-118. (doi:10.1016/j.contraception.2006.08.015)

Noyes RW, Hertig AT \& Rock J 1950 Dating the endometrial biopsy. Fertility and Sterility 1 3-25.

Ortiz ME, Ortiz RE, Fuentes MA, Parraguez VH \& Croxatto HB 2004 Post-coital administration of levonorgestrel does not interfere with post-fertilization events in the new-world monkey Cebus apella. Human Reproduction 19 1352-1356. (doi:10.1093/humrep/deh180)

Pietila M, Alhonen L, Halmekyto M, Kanter P, Janne J \& Porter CW 1997 Activation of polyamine catabolism profoundly alters tissue polyamine pools and affects hair growth and female fertility in transgenic mice overexpressing spermidine/spermine N1-acetyltransferase. Journal of Biological Chemistry 272 18746-18751. (doi:10. 1074/jbc.272.30.18746)

Pope WF 1988 Uterine asynchrony: a cause of embryonic loss. Biology of Reproduction 39 999-1003. (doi:10.1095/biolreprod39.5.999)

Popovici RM, Kao LC \& Giudice LC 2000 Discovery of new inducible genes in in vitro decidualized human endometrial stromal cells using microarray technology. Endocrinology 141 3510-3513. (doi:10. 1210 /en.141.9.3510)

Riesewijk A, Martin J, van Os R, Horcajadas JA, Polman J, Pellicer A, Mosselman S \& Simon C 2003 Gene expression profiling of human endometrial receptivity on days $\mathrm{LH}+2$ versus $\mathrm{LH}+7$ by microarray technology. Molecular Human Reproduction 9 253-264. (doi:10.1093/ molehr/gag037)

Robb L, Dimitriadis E, Li R \& Salamonsen LA 2002 Leukemia inhibitory factor and interleukin-11: cytokines with key roles in implantation. Journal of Reproductive Immunology 57 129-141. (doi:10. 1016/S0165-0378(02)00012-8) 
Rutanen EM, Salmi A \& Nyman T 1997 mRNA expression of insulinlike growth factor-I (IGF-I) is suppressed and those of IGF-II and IGF-binding protein-1 are constantly expressed in the endometrium during use of an intrauterine levonorgestrel system. Molecular Human Reproduction 3 749-754. (doi:10.1093/molehr/3.9.749)

Seppala M, Bohn H \& Tatarinov Y 1998 Glycodelins. Tumour Biology 19 213-220. (doi:10.1159/000030009)

Seppala M, Taylor RN, Koistinen H, Koistinen R \& Milgrom E 2002 Glycodelin: a major lipocalin protein of the reproductive axis with diverse actions in cell recognition and differentiation. Endocrine Reviews 23 401-430. (doi:10.1210/er.2001-0026)

Shafiq N, Malhotra S \& Pandhi P 2004 Comparison of nonselective cyclo-oxygenase (COX) inhibitor and selective COX-2 inhibitors on preimplantation loss, postimplantation loss and duration of gestation: an experimental study. Contraception 69 71-75. (doi:10. 1016/j.contraception.2003.08.010)

Song H, Lim H, Paria BC, Matsumoto H, Swift LL, Morrow J, Bonventre JV \& Dey SK 2002 Cytosolic phospholipase A2alpha is crucial [correction of A2alpha deficiency is crucial] for 'on-time' embryo implantation that directs subsequent development. Development 129 2879-2889.

Talbi S, Hamilton AE, Vo KC, Tulac S, Overgaard MT, Dosiou C, Le Shay N, Nezhat CN, Kempson R, Lessey BA et al. 2006 Molecular phenotyping of human endometrium distinguishes menstrual cycle phases and underlying biological processes in normo-ovulatory women. Endocrinology 147 1097-1121. (doi:10.1210/en.2005-1076)

Tapia A, Vilos C, Marín JC, Croxatto HB \& Devoto L 2011 Bioinformatic detection of E47, E2F1 and SREBP1 transcription factors as potential regulators of genes associated to acquisition of endometrial receptivity. Reproductive Biology and Endocrinology 9 1-14. (doi:10.1186/1477-7827-9-14)

Tapia A, Gangi LM, Zegers-Hochschild F, Balmaceda J, Pommer R, Trejo L, Pacheco IM, Munroe DJ, Croxatto HB \& Velasquez L 2008 The endometrial gene expression during the receptive period is different in women who were refractory to implantation in repeated cycles of oocyte donation and women who got pregnant in the same program. Human Reproduction 23 340-351. (doi:10.1093/humrep/ dem319)

Taylor RN, Vigne JL, Zhang P, Hoang P, Lebovic DI \& Mueller MD 2000 Effects of progestins and relaxin on glycodelin gene expression in human endometrial cells. American Journal of Obstetrics and Gynecology 182 841-847. (doi:10.1016/S0002-9378(00)70333-4)

Wallner BP, Mattaliano RJ, Hession C, Cate RL, Tizard R, Sinclair LK, Foeller C, Chow EP, Browning JL, Ramachandran KL et al. 1986 Cloning and expression of human lipocortin, a phospholipase A2 inhibitor with potential anti-inflammatory activity. Nature $\mathbf{3 2 0}$ 77-81. (doi:10.1038/320077a0)

Wilson MR, Roeth PJ \& Easterbrook-Smith SB 1991 Clusterin enhances the formation of insoluble immune complexes. Biochemical and Biophysical Research Communications 177 985-990. (doi:10.1016/0006-291X(91)90635-K)

Received in final form 21 October 2011

Accepted 3 November 2011

Made available online as an Accepted Preprint 3 November 2011 